\title{
Evaluation of pesticide residues in fruit from Poland and health risk assessment
}

\author{
B. Łozowicka*, P. Kaczyński, E. Rutkowska, M. Jankowska, I. Hrynko
}

Plant Protection Institute-National Research Institute, Laboratory of Pesticide Residues, Chełmońskiego 22, Białystok 15-195, Poland; ${ }^{*}$ Corresponding Author: B.Lozowicka@iorpib.poznan.pl

Received 2013

\section{ABSTRACT}

In the present study an effort has been made to evaluate the residues of insecticides, fungicides and herbicides in fruit from Poland and their health risks assessed. Accredited multiresidue methods based on gas and liquid chromatography, and spectroscopic technique were used to determine the concentrations above 160 pesticides. A total of 392 samples of 15 different fruit were collected during the May 2010 to October 2012 . In $48.2 \%$ of samples no residues were found, $45.9 \%$ of samples contained pesticide residues at or below the EU MRL, and $5.9 \%$ of samples contained pesticide residues above MRL. Sour cherries (66\%) and apples (63\%) were the commodities in which pesticide residues the most frequently occurred. Thirty one different pesticides were detected in total. Dithiocarbamate, captan, cyprodinil and boscalid were the pesticide most frequently found. Multiple pesticides ( $>1$ pesticide) were detected in about $30.1 \%$ samples. The dietary intake of residues of some pesticides can pose acute hazards. Data obtained were used for estimating the potential health risks associated with the exposures to these pesticides. The highest estimated daily intakes (EDIs) for children were: $22 \%$ for dimethoate and $112 \%$ for diazinone of the ADI. The most critical commodity was apple, contributing 1.30 to the acute Hazard Index for flusilazole. The results show that despite a high occurrence of pesticide residues in fruit it could not be considered a serious public health problem. Nevertheless, an investigation into continuous monitoring of pesticide residues in fruit is recommended.

Keywords: Pesticides; Analytical Methods; Fruit; Poland; Risk Assessment

\section{INTRODUCTION}

Fruit are one of the supplementary sources of carbohydrates, lipids, vitamins, minerals, antioxidants and other important nutrients. The consumption of these commodities with vegetables is almost $160 \mathrm{~kg} /$ per capita/year in Europe. A high intake of fruit has been encouraged not only to prevent consequences due to vitamin deficiency but also to reduce the incidence of major diseases such as cancer [1], cardiovascular diseases and obesity. But fresh fruit could also be a potential source of harmful and toxic substances. Thus, food safety has become a major public concern worldwide [2].

Pesticides are chemical substances, which are commonly used in modern agriculture practices to protect the crops from different pests and diseases [3]. Like other crops, fruit are attacked by pests and diseases during production and storage leading to damages that reduce the quality and the yield. The use of pesticides have increased because they have rapid action, decrease toxins produced by ford infecting organisms and are less labor intensive than other pest control methods.

However, the use of pesticides during production often leads to the presence of pesticide residues in fruit after harvest. Unfortunately, not all farmers follow legal practices with pesticides during production. Therefore, pesticides should be controlled at optimum level due to their relative toxicity to the human health. Pesticide residue analysis is tremendously an important process in determining the safety of using certain pesticides. A number of analytical methods are designed to determine multiple pesticide residues. In the past few years, new extraction procedures have been developed, such as solid-phase microextraction [4] and supercritical fluid extraction [5]. Pesticides are usually determined by gas chromatography (GC), GC-mass spectrometry, GC-ion trap mass spectrometry [6] and GC-tandem mass spectrometry [7]. Besides GC-MS methods, there are other traditional quantification methods like high performance liquid chromatography (HPLC) [8], HPLC-mass spectrometry, low-pressure gas chromatography-mass spectrometry [9] and liquid chromatography-tandem mass spectrometry. 
In our research, accredited multiresidue methods based on gas and liquid chromatography, and spectroscopic technique were used to determine the concentrations above 160 pesticides.

Fruit have been given a lot of attention in monitoring programs each country since most of them are eaten raw, it is expected that they contain higher pesticide residue level compared to other food groups of plant origin. According to the Pesticide Residues Committee in the UK, consumers are encouraged to eat at least five portions of fruit and vegetables daily. Poland is an important fruit, particularly apples, exporting area in to the Europe and Russia. Therefore, assessing the risk of pesticide residues in these commodities intended for human consumption is necessary.

The purpose of this paper was to present data on pesticide residues in fruit from Poland carried out in 20102012. Pesticide residue levels were evaluated in relation to: Acceptable Daily Intakes (ADIs) [10] cute Reference Doses (ARfDs) and Maximum Residue Levels (MRLs) derived from toxicological studies. The results can be used when designing future control programs for this region and taking preventive actions to minimize human health risks.

\section{MATERIAL AND METHODS}

\subsection{Standards, Reagents and Chemicals}

Pesticide reference standards were purchased from Dr. Ehrenstorfer (Augsburg, Germany). Pesticide standard stock solutions (purity higher than 95\%) of various concentrations were prepared in acetone and stored in dark below $4^{\circ} \mathrm{C}$.

All solvents used were analytical grade from J.T. Baker (Deventer, Holland), as well as florisil (60 - 100 mesh) and phosphate buffer $\mathrm{pH}=8$. Silica gel (230 - 400 mesh), sodium sulfide nonahydrate and celite were obtained from Merck (Darmstadt, Germany).

\subsection{Samples}

A total of 392 samples of various fruit (apples $-38.8 \%$, strawberries $-19.1 \%$, sour cherries $-12.8 \%$, currants $9.7 \%$, pears $-6.6 \%$, plums $-3.8 \%$, raspberries $-3.3 \%$, black chokeberries $-3.1 \%$ and other $-2.8 \%$ ) were collected from Poland.

\subsection{Analytical Procedure}

Sample preparation was done using three methods: multiresidue method (MRM) for determination of 159 pesticide residues This method was described in our previously study [11] and two single residue method (SRM) $[12,13]$. Figure 1 presents all sample preparation methods and instrumental analysis used for determination pesticide residues in fruit samples.

\subsection{Quality Check}

The laboratory successfully participated in the proficiency testing schemes organized and run by the European Commission (University of Almeria) and by the Food Analysis Performance Assessment Scheme (FAPAS; Central Science Laboratory in York). All of the analyses were conducted with the use of an accredited method by the Polish Centre of Accreditation (PCA).

\subsection{Method Validation}

The validation of the analytical methods was carried out in accordance with European Commission (EC) guidelines [14]. The validation studies were performed using pesticide-free fruit samples, previously analyzed. Calibration standards were prepared in matrix solution to produce a final concentration of three spiking levels $(0.005$ to $0.05 \mathrm{mg} / \mathrm{kg}, 0.05-0.5 \mathrm{mg} / \mathrm{kg}$ and $0.25-2.5$ $\mathrm{mg} / \mathrm{kg}$ ). Method accuracy and precision were evaluated by performing recovery studies and are expressed as relative standard deviation (RSD, \%) and mean recovery, respectively. Repeatability was calculated for five days using five replicates for each level of three different concentration levels. The sensitivity was evaluated by determining the limit of detection (LOD) and the limit of quantification (LOQ) of the assay. The LOD and LOQ were calculated using the signal-to-noise ratio $(\mathrm{S} / \mathrm{N})$ criteria in all cases $(\mathrm{LOD}=3 \mathrm{~S} / \mathrm{N}, \mathrm{LOQ}=10 \mathrm{~S} / \mathrm{N})$.

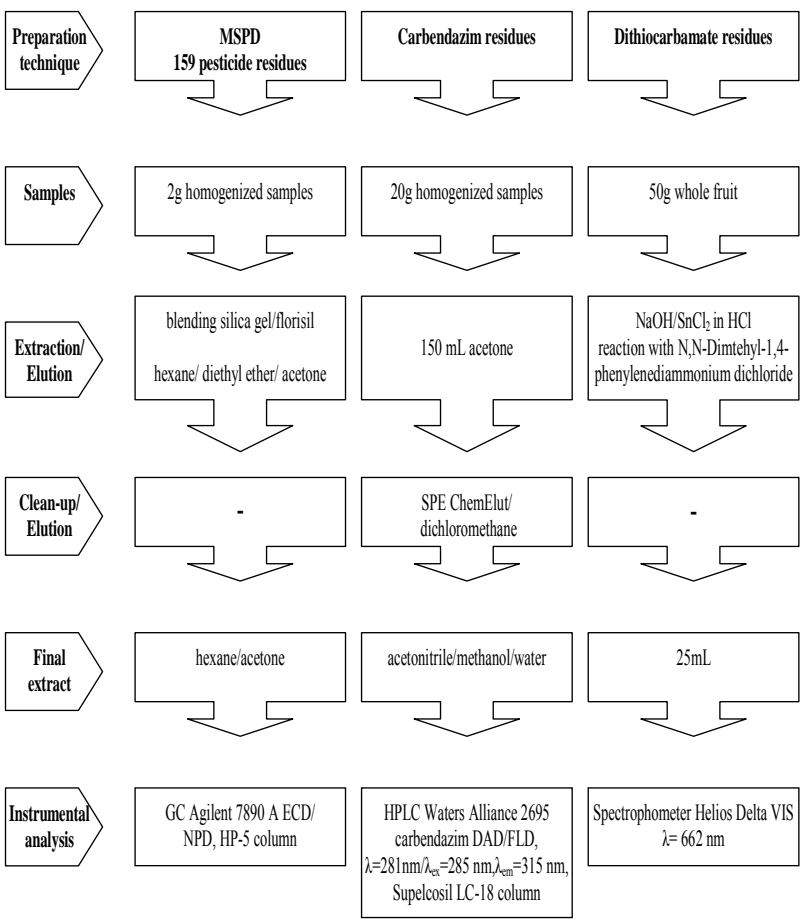

Figure 1. Scheme of sample preparation procedures. 


\subsection{Risk Assessment}

Consumption data play a major role in the dietary risk assessment of residues in food. This risk was calculated through the comparison of found residues to the established acceptable daily intake (ADI) and Acute References Doses (ARfD) values. The level of residue concentration in a product was determined as the arithmetic mean of all the results obtained. Results under LOD of analytical methods used for intake calculations were taken as LOD values. Values of ADI and ARfD are elaborated by Joint FAO/WHO Meeting on Pesticides Residues [15]. For consumer residues intake estimation were applied new model from Pesticides Safety Directorate (PSD) of the Department for Environment, British Food and Rural Affairs [16]. Calculations were performed for two subpopulations: small children (1.5 - 4 years) and adults accepting consumption at the level of the 97.5 percentile. The estimated daily intake $(E D I)$ of pesticide residues was calculated as follows:

$$
E D I=\sum \frac{F_{i} \times R L_{i}}{\text { mean_body_weight }}
$$

where: $F_{i}$ - food consumption data, $R L_{i}$ - residue level to the commodity.

The long-term risk assessment of the intakes compared to the pesticide toxicological data were performed by calculating the hazard quotient $(H Q)$, by dividing the estimated daily intake with the relevant acceptable daily intake:

$$
H Q=\frac{E D I}{A D I} \cdot 100 \%
$$

The HQ was calculated both for pesticides and commodities. The HQs are summed up to give a chronic hazard index $(c \mathrm{HI})$ :

$$
c H I=\sum H Q
$$

Estimate of Short-Term Intake (ESTI) was calculated according to the following formula:

$$
E S T I=\sum \frac{F \times H R . P}{\text { mean_body_weight }}
$$

where: $F$ - full portion consumption data for the commodity unit, HR.P - the highest residue level.

An estimate of intake of pesticide in the diet was to compare to the ARfD. The acute hazard index was calculated as follows:

$$
a H I=\frac{E S T I}{A R f D}
$$

\section{RESULTS AND DISCUSSION}

Based on our analytical studies pesticide residues were not observed in $48.2 \%$ of fruit samples (189). Whereas pesticide residues were found in 203 samples (51.8\%). In most of analysed samples $(45.9 \%)$ pesticide residues were below MRLs, while in 5.9\% (23) above safety limits (MRLs). Pesticide residue levels were compared to EU-MRLs [17].

\subsection{Multiresidue Samples}

Samples containing one (21.7\%), as well as multiple active substances: two, three and even seven residues presents Figure 2.

Most commonly detected were combination of two pesticides: flusilzole/dithiocarbamates, captan/dithiocarbamates and cyprodinil/fludioxonil.

\subsection{Detected Groups of Pesticides}

As present Figure 3 the most occurrence group was fungicides $(81.7 \%)$. The most frequently detected active substances among them were: dithiocarbamates (104 samples) range 0.05 to $1.87 \mathrm{mg} / \mathrm{kg}$ and captan (80) range 0.01 to $2.83 \mathrm{mg} / \mathrm{kg}$.

Chlorpiryfos (13) range 0.03 to $0.04 \mathrm{mg} / \mathrm{kg}$, fenazaqui n (10) range 0.02 to $0.240 \mathrm{mg} / \mathrm{kg}$, and acetamipiryd (9) range 0.01 to $0.03 \mathrm{mg} / \mathrm{kg}$, were dominated among insecticides.

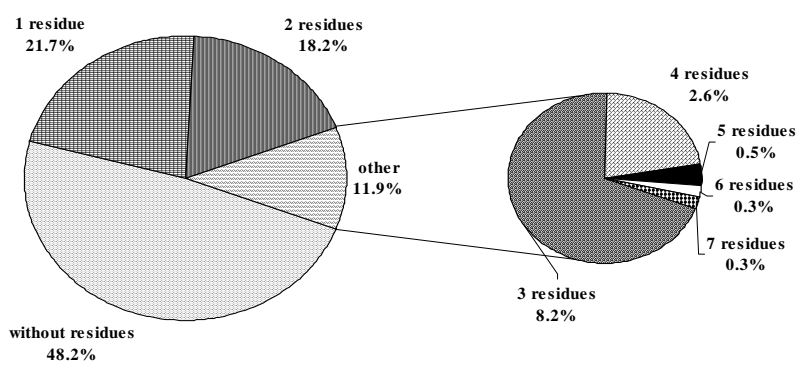

Figure 2. Samples of fruit: without, with one and multiresidue pesticides.

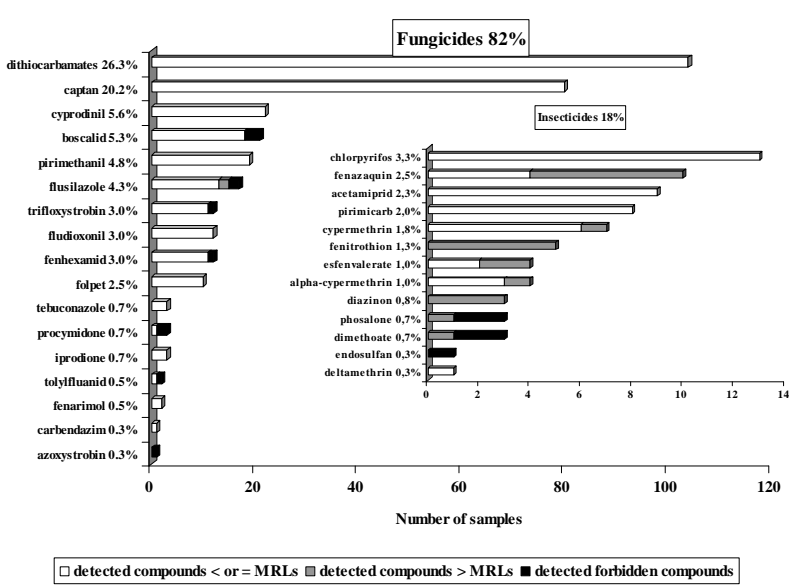

Figure 3. Fungicides and insecticides detected in fruit samples. 


\subsection{Pesticide Residues in Fruit}

The highest percentage of detected pesticide residues showed sour cherry samples (66\%). Grape, chokeberry, blackberry, elderberry, wild strawberry, rose hips and sea sallow thorn samples were free from residues. Apples contained 59.2\% samples with residues below MRL and $3.9 \%$ above MRL. The most frequently detected pesticides in apple samples were: dithiocarbamates range 0.05 to $1.87 \mathrm{mg} / \mathrm{kg}$, captan range 0.01 to $0.06 \mathrm{mg} / \mathrm{kg}$, pirymethanil range 0.01 to $0.27 \mathrm{mg} / \mathrm{kg}$, boscalid range 0.02 to $0.26 \mathrm{mg} / \mathrm{kg}$, trifloxystrobin 0.01 to $0.100 \mathrm{mg} / \mathrm{kg}$, diazinon range 0.02 to $0.03 \mathrm{mg} / \mathrm{kg}$, dimethoate range 0.01 to $0.03 \mathrm{mg} / \mathrm{kg}$, flusilazole range 0.01 to $0.09 \mathrm{mg} / \mathrm{kg}$ and phosalone range 0.01 to $0.25 \mathrm{mg} / \mathrm{kg}$. Currant contained $21 \%$ samples with residues below MRL and 39.5\% above MRL and not authorized for use. The largest number of active substances in these samples was detected, from 3 residues to 7 residues (Figure 2). The most frequently detected pesticide above the permissible limits were dithiocarbamates range 0.05 to $0.85 \mathrm{mg} / \mathrm{kg}$, fenazaquin range 0.05 to $0.24 \mathrm{mg} / \mathrm{kg}$, fenitrothion range 0.02 to $0.03 \mathrm{mg} / \mathrm{kg}$, esfenwalerate range 0.02 to 0.15 $\mathrm{mg} / \mathrm{kg}$ and flusilazole range 0.01 to $0.09 \mathrm{mg} / \mathrm{kg}$. Strawberries contained $40 \%$ of samples with residues below MRL and 1.3\% above MRL. 17 multiresidue samples strawberries containing from 2 to 3 pesticides were recorded. There were also cases where not authorized fungicides were detected (procymidone and tolylfluanid). Raspberry samples with residues below MRL contained $38.5 \%$ of samples. There were two and three multiresidue samples detected.

\subsection{Risk of Exposure}

In order to assess the risk of exposure of human health to the pesticide residues, first of all, the individual components of dietary intakes must be known [10], taking into account different age groups (e.g. infants, toddlers, school children, adults etc.), as it relates to body weight and nutritional prevention. The assessment of chronic (long-term) health risk of consumers connected with the consumption of apples from north-east Poland containing pesticide residues was conducted on the basis of available epidemiological studies done for the British. There is a lack of full studies done for Polish consumers since these studies only take into account general population and average consumption (50 percentile) [18], and therefore had no practical application in the current study. Accordingly, 13 GEMS/Food Consumption Cluster Diets were developed based on FAO Food Balance Sheet data from 183 countries.

The average intake for each food item at the cluster level was weighed by the population size of the reporting country. The western and central parts of Europe, such as the United Kingdom, Poland, Germany, etc., have been classified into the same Consumption Cluster Diets E [19].

During the assessment of the long-term consumer risk the study assumed a cautious approach by using conservative guidelines, which inflated the risk. Based on the results (Table 1), the chronic intakes of the thirty one considered pesticide residues are rather low compared to the ADI (mostly the $c \mathrm{HI}$ were $<1 \%$ ).

Table 1. Health risk estimation for chronic effects associated with average pesticide residue.

\begin{tabular}{|c|c|c|c|c|c|c|c|}
\hline \multirow[b]{2}{*}{$\begin{array}{c}\text { Active } \\
\text { substance }\end{array}$} & \multirow{2}{*}{$\begin{array}{c}\text { ADI } \\
\text { bw/day }\end{array}$} & \multicolumn{3}{|c|}{ ADULT } & \multicolumn{3}{|c|}{ TODDLER } \\
\hline & & $\begin{array}{l}\text { bw/day } \\
\times 10^{-4}\end{array}$ & $c \mathrm{HI}$ & $\begin{array}{c}\text { Health } \\
\text { risk }\end{array}$ & $\begin{array}{c}\mathrm{mg} / \mathrm{kg} \\
\mathrm{bw} / \mathrm{day} \\
\times 10^{-4}\end{array}$ & $c \mathrm{HI}$ & $\begin{array}{c}\text { Health } \\
\text { risk }\end{array}$ \\
\hline acetamipirid & 0.07 & 0.3 & $<1$ & No & 1.7 & $<1$ & No \\
\hline $\begin{array}{c}\text { alpha- } \\
\text { cypermethrin }\end{array}$ & 0.015 & 0.2 & $<1$ & No & 0.6 & $<1$ & No \\
\hline azoxystrobin & 0.2 & 0.7 & $<1$ & No & 1.5 & $<1$ & No \\
\hline boscalid & 0.04 & 1.0 & $<1$ & No & 3.7 & $<1$ & No \\
\hline captan & 0.1 & 2.3 & $<1$ & No & 9.3 & $<1$ & No \\
\hline carbendazim & 0.02 & 0.5 & $<1$ & No & 3.0 & 2 & No \\
\hline chlorpyrifos & 0.01 & 0.5 & $<1$ & No & 2.3 & 2 & No \\
\hline $\begin{array}{l}\text { chlorpyrifos } \\
\text { methyl }\end{array}$ & 0.01 & 0.1 & $<1$ & No & 0.4 & $<1$ & No \\
\hline cypermethrin & 0.05 & 1.7 & $<1$ & No & 7.2 & 1 & No \\
\hline cyprodinil & 0.03 & 0.5 & $<1$ & No & 2.5 & $<1$ & No \\
\hline deltamethrin & 0.01 & 0.0 & $<1$ & No & 0.2 & $<1$ & No \\
\hline diazinon & 0.0002 & 0.4 & 22 & No & 2.2 & 112 & Yes \\
\hline dimethoate & 0.001 & 0.6 & 6 & No & 2.2 & 22 & No \\
\hline $\begin{array}{l}\text { dithiocar- } \\
\text { bamates }\end{array}$ & 0.05 & 5.5 & 1 & Jo & 22.4 & 4 & No \\
\hline endosulfan & 0.006 & 0.2 & $<1$ & No & 0.7 & 1 & No \\
\hline esfenvalerate & 0.02 & 0.7 & $<1$ & No & 3.4 & 2 & No \\
\hline fenarimol & 0.01 & 0.1 & $<1$ & No & 0.3 & $<1$ & No \\
\hline fenazaquin & 0.005 & 0.7 & 1 & No & 3.6 & 7 & No \\
\hline fenhexamid & 0.2 & 1.0 & $<1$ & No & 3.4 & $<1$ & No \\
\hline fenitrothion & 0.005 & 0.3 & $<1$ & No & 1.7 & 3 & No \\
\hline fludioxonil & 0.37 & 0.2 & $<1$ & No & 0.6 & $<1$ & No \\
\hline flusilazole & 0.002 & 0.4 & 2 & No & 1.9 & 9 & No \\
\hline folpet & 0.1 & 0.9 & $<1$ & No & 4.2 & $<1$ & No \\
\hline iprodione & 0.06 & 0.2 & $<1$ & No & 0.9 & $<1$ & No \\
\hline phosalone & 0.01 & 0.3 & $<1$ & No & 1.8 & 2 & No \\
\hline pirimicarb & 0.035 & 0.5 & $<1$ & No & 2.1 & $<1$ & No \\
\hline pirimethanil & 0.17 & 0.5 & $<1$ & No & 2.7 & $<1$ & No \\
\hline procymidone & 0.0028 & 0.5 & 2 & No & 1.0 & 4 & No \\
\hline tebuconazole & 0.03 & 0.4 & $<1$ & No & 1.8 & $<1$ & No \\
\hline tolylfluanid & 0.1 & 0.2 & $<1$ & No & 0.5 & $<1$ & No \\
\hline $\begin{array}{l}\text { triflok- } \\
\text { systrobin }\end{array}$ & 0.1 & 0.5 & $<1$ & No & 2.5 & $<1$ & No \\
\hline HI - Hazard In & $x[\%]$ & & $\mathrm{g} / \mathrm{kg}$ & & & & \\
\hline
\end{tabular}


The safety of Polish consumer (adults) thus seems to be generally under control in terms of pesticide intakes through fruit and vegetables consumption. Nevertheless, some residues such as diazinon and dimethoate need to be considered more closely given that for a high consumer ( 97.5 percentile) the $\mathrm{cHI}$ were $22 \%$ and $6 \%$ of the ADI respectively.

With respect to children the ADI was significantly exceeded for diazinon at high and frequent fruit consumption (apples), with the $\mathrm{cHI} 112 \%$. This compound, belonging to the organophosphate insecticide group had the lowest ADI value, at $0.0002 \mathrm{mg} / \mathrm{kg}$ body weight of all of the pesticides being studied. It should be noted that the residues of diazinon were found in only five of the 392 of tested samples.

Short-term exposure expressed as acute hazard index $(a H I)$ for children based on the highest consumption at 97.5 percentile and highest concentrations of pesticides residues detected in fruit are presented in Table 2. In the all of cases which exceed the MRLs only apple sample containing flusilazole at concentration $0.09 \mathrm{mg} / \mathrm{kg}$ constituted a real threat children health $(a H I=1.297)$. The acute risk especially from dimethoate in plum is high and $a H I$ value approaches the limit value is equal to $1(a H I=$ 0.946 ).

In our work the assessment was based on worst-case scenarios: the consumption data for consumers who eat a large portion size of the food were combined with the highest residue found in fruit from north-eastern Poland.

The evaluation of consumer health risk connected with the contamination of fruit and vegetables with pesticide residues shows that it did not pose a danger to neither subpopulation of small children or adults.

The only noted possible risk for small children was connected with the residues of diazinon. Children are a vulnerable group of fruit and vegetables consumers, who are due to their lower body weight, exposure to relatively higher pesticide residue levels. A more profound study regarding this consumer group is recommended.

\section{CONCLUSIONS}

In conclusion, the results showed that the majority of fruit samples were in conformity with the relevant legislation and did not contain detectable pesticide residues (48.2\%). Pesticide residues were found in $45.9 \%$ of all monitored fruit samples at or below MRL. While, 5.9\% of samples were above MRL, however, they did not pose a threat for public health, as demonstrated by the outcomes of dietary risk assessment.

The results obtained suggest that despite the consumers are exposed to various concentrations of pesticide residues in fruit from Poland there is no reason for concern and health risk can be excluded.

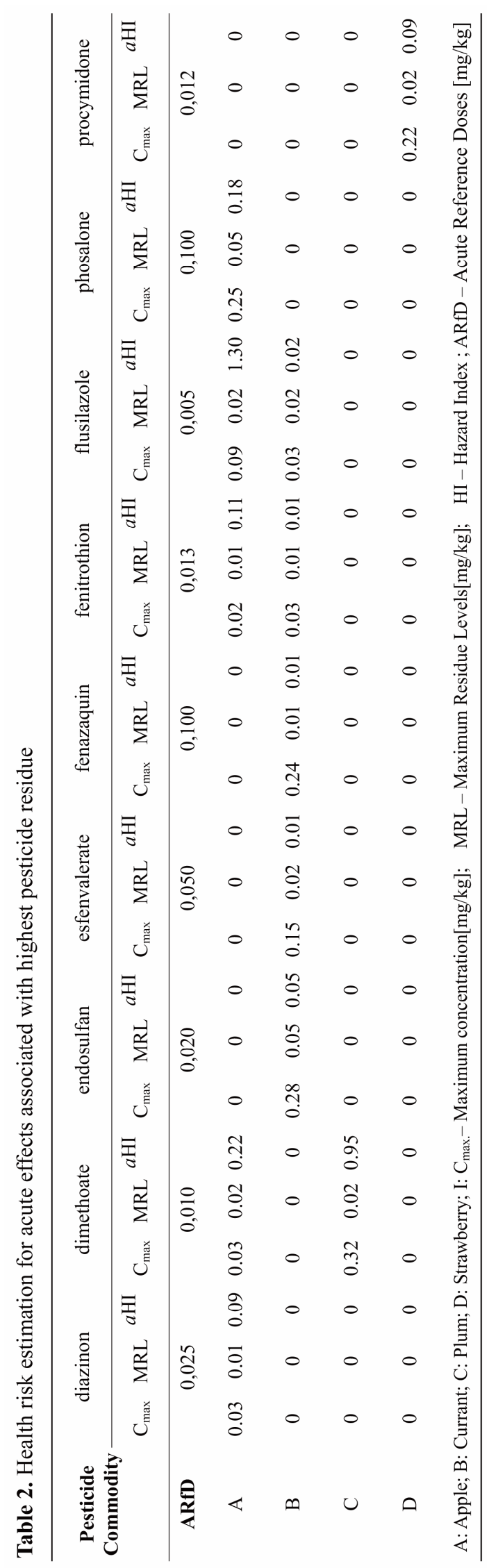


Nevertheless, on the basis of above findings, the need for residue control programs for pesticides in all fruit commodities is recommended to protect the consumer for indiscriminate exposure of pesticides. A future studies in this area in a longer period of time are required and would gain a deeper knowledge about the fruit produced in this country with respect to the use of plant protection products and their presence in samples.

\section{REFERENCES}

[1] Wattenberg, L.W. (1992) Inhibition of carcinogenesis by minor dietary constituents. Cancer Research, 52, 20852091.

[2] Radwan, M.A. and Salama, A.K. (2006) Market basket survey for some heavy metals in Egyptian fruit and vegetables. Food and Chemical Toxicology, 44, 1273-1278. doi:10.1016/j.fct.2006.02.004

[3] Guler, G.O., Cakmak, Y.S., Dagli, Z., Aktumsek, A. and Ozparlak, H. (2010) Organochlorine pesticide residues in wheat from Konya region, Turkey. Food and Chemical Toxicology, 48, 1218-1221. doi:10.1016/j.fct.2010.02.013

[4] Abdulrauf, L.B., Chai, M.K. and Tan, G.H. (2012) Applications of solid-phase microextraction for the analysis of pesticide residues in fruit and vegetables: A review. Journal of AOAC International, 95, 1272-1290. doi:10.5740/jaoacint.SGE_Abdulrauf

[5] Lehotay, S.J. (1996) Supercritical fluid extraction of pesticide residues in fruit and vegetables. Seminars in Food Analysis, 1, 73-84

[6] Tao, C.J., Hu, J.Y., Li, J.Z., Zheng, S.S., Liu, W. and Li, C.J. (2009) Multi-residue determination of pesticides in vegetables by gas chromatography/ion trap mass spectrometry. Bulletin of Environmental Contamination and Toxicology, 82, 111-115. doi:10.1007/s00128-008-9528-0

[7] Vidal, J.L.M., Arrebola, F.J. and Mateu-Sanchez, M. (2002) Application of gas chromatography-tandem mass spectrometry to the analysis of pesticides in fruit and vegetables. Journal of Chromatography A, 959, 203-213. doi.org/10.1016/S0021-9673(02)00444-2

[8] Parveen, Z., Khuhro, M.I. and Rafiq, N. (2005) Monitoring of pesticide residues in vegetables (2000-2003) in Karachi, Pakistan. Bulletin of Environmental Contamination and Toxicology, 74, 170-176. doi:10.1007/s00128-004-0564-0
[9] Walorczyk, S. and Gnusowski, B. (2006) Fast and sensitive determination of pesticide residues in vegetables using low-pressure gas chromatography with a triple quadrupole mass spectrometer. Journal Chromatography A, 1128, 236-243. doi:10.1016/j.chroma.2006.06.044

[10] WHO (1997) Guidelines for predicting dietary intake of pesticide residues. 2nd revised edition, GEMS/Food Document WHO/FSF/FOS/97.7, Geneva.

[11] Łozowicka, B., Jankowska, M. and Kaczyński, P. (2011) Pesticide residues in Brassica vegetables and exposure assessment of consumers. Food Control, 25, 561-575. doi:10.1016/j.foodcont.2011.11.017

[12] Łozowicka, B. and Kaczyński, P. (2009) Determination of carbendazim, linuron and glyphosate residues by HPLC method. Polish Journal Environmental Studies, 18, 100-104.

[13] Łozowicka, B. and Kaczyński, P. (2009) Dithiocarbamate residues in food and the potential risk for consumers. Bromat. Chem. Toksyn., 4, 1155-1160.

[14] SANCO: Method validation and quality control procedures for pesticide residues analysis in food and feed. Document No. SANCO/10684/2009, 2009.

[15] WHO (World Health Organization) (2003) Inventory of ICPS and Rother WHO Pesticides evaluations and summary of toxological evaluations performed by the Joint Meeting on Pesticide Residues (JMPR), WHO/PCS/02.3. http://www.who.int.pcs.

[16] PSD (Pesticides Safety Directorate) (2006) New intake calculation models for consumer intake assessments. http://www.detergents.gov.uk

[17] Regulation (EC) No 396/2005 of the EC of 23 February 2005 on maximum residue levels of pesticides in or on food and feed of plant and animal origin and amending Council Directive 91/414/EEC as follows changes.

[18] Szponar, L., Sekuła, W., Rychlik, E., Ołtarzewski, M. and Figurska, K. (2003) The household food consumption and anthropometric survey in poland. project report TCP/POL/8921(A), National Food and Nutrition Institute, Warszawa, 2003.

[19] Global Environment Monitoring System-Food Contamination Monitoring and Assessment Programme (GEMS/Food). (2012) GEMS/Food Cluster Diets. World Health Organization.

http://www.who.int/foodsafety/chem/gems/en/index1.htm 1 